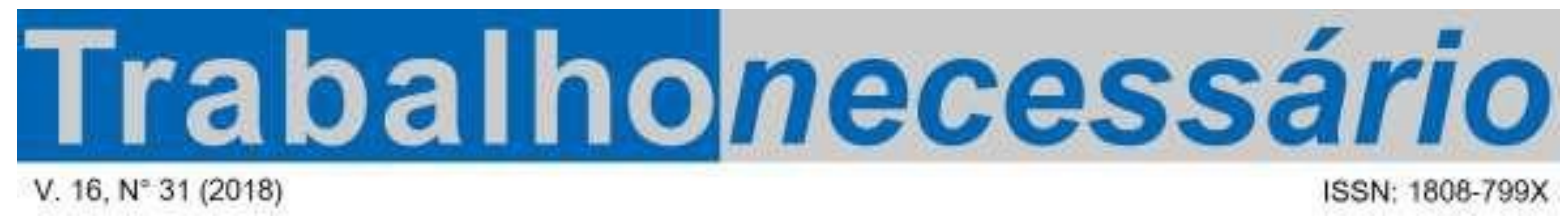

\title{
A ESCOLA UNITÁRIA EM GRAMSCI E A EDUCAÇÃO PROFISSIONAL NO BRASIL 1
}

Neila Pedrotti Drabach ${ }^{2}$

\begin{abstract}
Resumo
O trabalho situa o contexto em que é elaborada a proposta de escola unitária por Antônio Gramsci, tendo como base os "Cadernos do Cárcere", e toma essa concepção para analisar a educação profissional no Brasil. Com vistas nisso, aborda os principais conceitos do pensamento gramsciano, a fim de situar o papel da escola e a proposta de escola unitária na perspectiva desse teórico, e apresenta um panorama das iniciativas públicas federais de educação profissional no Brasil, no contexto contemporâneo, cotejando-as a partir da concepção de educação do marxista sardo. Conclui apontando que muitas das críticas dirigidas por Gramsci à escola italiana de sua época estão presentes na educação brasileira e que a construção de uma escola única, que contemple formação humanista e formação para o trabalho, constitui-se, ainda, um objetivo a ser alcançado.
\end{abstract}

Palavras-Chave: Escola Unitária, Educação Profissional, Políticas Educacionais

\section{GRAMSCI'S UNITARY SCHOOL AND PROFESSIONAL EDUCATION IN BRAZIL}

\begin{abstract}
The present paper situates the context in which Antônio Gramsci's unitary school proposal is elaborated, based on the "Cadernos do Cárcere", and takes this conception to analyze professional education in Brazil. With this in mind, the main concepts of Gramscian thought are approached, in order to situate the role of the school and the proposal of a unitary school in the perspective of this theoretician, and presents a panorama of the federal public initiatives of professional education in Brazil, in the contemporary context, comparing them from the conception of education by the Sardinian Marxist. He concludes by pointing out that many of the criticisms directed by Gramsci at the Italian school of his time are present in Brazilian education and the construction of an unique school, which contemplates humanistic formation and training for work, is also an objective to be achieved.
\end{abstract}

Keywords: Unitary School, Professional Education, Educational Policies

1DOI: https://doi.org/10.22409/tn.16i31.p27380

2Doutoranda em Educação pela Universidade de São Paulo - USP. Pedagoga vinculada ao Instituto Federal Farroupilha - IFFar. 


\section{Considerações Iniciais}

Não por acaso os escritos für $\mathrm{ewig}^{2}$ do marxista Antonio Gramsci abordaram a temática da escola. Concebendo-a como central no processo de construção da hegemonia das classes subalternas, a escola, para Gramsci, tem um importante papel na difusão da cultura e na formação de intelectuais, a par de outros espaços sociais, sendo esta uma função für ewig na sociedade em qualquer período histórico.

Contrapondo-se à organização e à função da escola italiana de sua época, a qual era diferenciada entre os grupos sociais, com currículos pragmáticos e especializados, Gramsci defendia a criação de uma escola única "de cultura geral, humanista, formativa, que equilibre de modo justo o desenvolvimento da capacidade de trabalhar manualmente (...) e o desenvolvimento das capacidades de trabalho intelectual" (GRAMSCl, 2014b, C12, p. 34). Essa concepção de escola permanece, para muitos educadores, um objetivo a ser concretizado em nosso país, uma vez que continuamos presenciando uma série de iniciativas que pulverizam diferentes instituições e programas educacionais (públicos e privados) direcionados a diferentes classes e frações de classe, de acordo com sua função na sociedade capitalista, ao lado de uma grande parcela da população que evade ou sequer chega à escola.

Para compreendermos o papel da escola/educação no pensamento de Gramsci, é necessário situá-la no âmbito da sua reflexão teórica mais ampla, preocupada com a construção de um projeto de mudança social. Assim, conceitos políticos como o de hegemonia, sociedade civil, sociedade política e intelectual são importantes para situar o papel da educação na "reforma intelectual e moral" necessária para a construção do socialismo, conforme vislumbrava o marxista sardo.

Com vistas nisso, esse trabalho irá abordar, de forma sumária, os principais conceitos do pensamento gramsciano a fim de situar o papel da escola e a proposta de escola unitária, na perspectiva desse teórico. A par disso, apresenta-se um

panorama das iniciativas públicas federais de educação profissional no Brasil, no contexto contemporâneo, cotejando-as a partir da concepção de escola unitária.

\footnotetext{
${ }^{2}$ Ao contrário dos escritos políticos publicados no jornal L'ordine Nuovo, os quais eram destinados a "morrer ao final do dia", Gramsci pretendia, nos Cadernos do Cárcere, escrever algo para além disso, desinteressado, für ewig (para a eternidade).
} 


\section{O papel da escola na construção da hegemonia}

Durante o período de sua prisão pelo fascismo italiano (1926-1937), a preocupação de Gramsci com a derrota do movimento operário italiano nos anos 1920 e as novas formas de hegemonia burguesa na Europa Ocidental o levou a empreitar uma reflexão que ampliou e renovou o marxismo, refutando as teses reformistas e maximalistas de sua época. De acordo com Lincoln Secco (2006), o conceito central dos Cadernos do Cárcere, é o de Hegemonia. É este conceito, segundo o autor, que articula os temas trabalhados em sua obra:

A literatura, o jornalismo, o fordismo e outros assuntos aparecem como variantes formais da mesma persistência temática: a hegemonia. É o seu processo de constituição histórica, as suas diferentes maneiras de construir o consentimento nas diversas camadas sociais, os seus diversos mecanismos e funções institucionais que interessam a Antonio Gramsci (SECCO, 2006, p. 47).

O conceito de hegemonia é utilizado por Gramsci, nos Cadernos do Cárcere, para a compreensão do Rissorgimento italiano. Esta, aliás, é uma característica da reflexão gramsciana: partir sempre de situações concretas, históricas, uma vez que pensava não haver teoria política fora da história, contrapondo-se à visão evolucionista do marxismo presente na sua época (SECCO, 2006). Nessa direção, o conceito de hegemonia não pode ser pensando fora da realidade, em abstrato apenas, devendo ser entendido como um processo e não um conceito fixo.

Em linhas gerais, Gramsci utiliza o termo hegemonia para mostrar como a classe dominante constrói e mantém sua dominação política e cultural, ou seja, ideológica (intelectual e moral), sobre os demais grupos sociais, com base no consenso e na coerção, quando necessária. Ao analisar a formação do Estado Moderno italiano, período conhecido como Rissorgimento, a partir da vitória da corrente política dos moderados, Gramsci sintetiza o conceito de hegemonia:

O critério metodológico sobre o qual deve se basear o próprio exame é esse: a supremacia de um grupo social se manifesta de dois modos, como "domínio" e como "direção intelectual e moral". Um grupo social domina os grupos adversários, que visa a "liquidar" ou a submeter inclusive com força armada, e dirige grupos afins e aliados. Um grupo social pode e, aliás, deve ser dirigente já antes de conquistar o poder governamental (esta é uma das condições principais para a própria conquista do poder); depois, quando exerce 
o poder e mesmo se o mantém fortemente nas mãos, torna-se dominante mas deve continuar a ser também "dirigente" (GRAMSCI, 2002, C19, p. 62-63).

Nessa passagem, pode-se identificar a importância da sociedade civil na construção da hegemonia, antes mesmo de este grupo social chegar ao aparelho estatal, como no caso do grupo político dos moderados na Itália. Essa direção "intelectual e moral" exercida na sociedade civil irá sustentar e dar condições para o acesso ao poder do aparelho de Estado (sociedade política). Nesse sentido, Gramsci concebe o Estado não apenas como o aparelho estatal. Em sentido amplo, o Estado, na visão deste marxista, é formado pelo conjunto da sociedade civil e da sociedade política.

A sociedade civil e a sociedade política podem ser compreendidas como dois grandes planos superestruturais, ligados organicamente entre si e em relação à estrutura ${ }^{3}$. Gramsci assim descreve esses dois planos: "o que pode ser chamado de 'sociedade civil' (isto é, o conjunto de organismos designados vulgarmente como 'privados') e o da 'sociedade política' planos que correspondem, respectivamente, à função de 'hegemonia' que o grupo dominante exerce em toda a sociedade e àquela de 'domínio direto' ou de comando, que se expressa no Estado e no governo ‘jurídico"' (2014b, C12, p. 21).

Nessa direção, Gramsci identificava que a função do Estado na sua época não se reservava apenas ao papel de coerção, como Marx havia identificado no período oitocentista. A construção e manutenção da hegemonia da classe burguesa passou a se utilizar também da incorporação de reivindicações democrático-popular (consenso) e dos organismos de difusão da sua ideologia, a qual agiria como amálgama entre estrutura e superestrutura, ou seja, a manutenção do bloco histórico ${ }^{4}$ sob o seu domínio. É importante ressaltar que, para Gramsci, ideologia significa uma visão de mundo, a qual implica em uma forma de pensar e de agir. Conforme sintetiza Silva, "a ideologia abarca um conjunto de ideias que dão conta de explicar e projetar uma realidade, de pautar uma concepção de mundo para determinado sujeito, coletivo ou não" (2010, p. 68).

3 Como descrevia Gramsci: "as forças materiais [estrutura] são o conteúdo e as ideologias [superestrutura] são a forma" e ainda ressaltava a "distinção entre conteúdo e forma é puramente didática, já que as forças materiais não seriam historicamente concebíveis sem forma e as ideologias seriam fantasias individuais sem as forças materiais" (2014a, C7, p. 238).

4 A identificação entre o "conteúdo econômico-social [estrutura] e a forma ético-política [superestrutura]" forma o bloco histórico (GRAMSCI, 2014a, C10, p. 308) 
Nesse sentido, sociedade política e sociedade civil compõem o Estado integral, na visão de Gramsci. Enquanto na primeira estão compreendidos os mecanismos pelos quais a classe dominante detém o monopólio legal da repressão e da violência, representados pelo controle da burocracia administrativa, do ordenamento jurídico e dos aparatos de força militar e policial, na segunda, estão compreendidas as organizações responsáveis pela elaboração e difusão das ideologias. Estas organizações são compreendidas pelo sistema escolar, pelas igrejas, pelas famílias, pelos partidos políticos, pelos sindicatos, pelas organizações profissionais, pelas organizações da imprensa (revistas, jornais, rádio, televisão, etc), entre outros (PORTELLI, 2002). Assim, não há como fazer uma separação entre sociedade política e sociedade civil, ambas, através de uma relação orgânica, visam manter a dominação pela classe fundamental, combinando consenso e coerção.

A construção/manutenção da hegemonia de uma classe é exercida, segundo Gramsci, pelos intelectuais: que são os "funcionários" da superestrutura. Conforme aponta o autor:

Os intelectuais são os "prepostos" do grupo dominante para o exercício das funções subalternas de hegemonia social e do governo político, isto é: 1) do consenso "espontâneo" dado pelas grandes massas da população à orientação impressa pelo grupo fundamental dominante à vida social, consenso que nasce "historicamente" do prestígio (e, portanto, da confiança) obtida pelo grupo dominante por causa de sua posição e de sua função no mundo da produção; 2) do aparelho de coerção estatal que assegura "legalmente" a disciplina dos grupos que não "consentem", nem ativa nem passivamente, mas que é construído para toda a sociedade na previsão dos momentos de crise no comando e na direção, nos quais desaparece o consenso espontâneo (GRAMSCI, 2014b, C12, p. 21).

Gramsci parte do ponto de vista de que todo homem é um intelectual, no entanto, nem todos exercem a função de intelectual na sociedade, ou seja, o papel de organização e difusão da ideologia de uma classe. Os intelectuais são fundamentais para o exercício da hegemonia, pois são eles que atuam na construção da forma ético-política necessária ao conteúdo econômico-social do modo de produção. Nas palavras do autor, "Por intelectuais, deve-se entender [...] todo o estrato social que exerce funções organizativas em sentido lato, seja no campo da produção, seja no da cultura e no político-administrativo" (GRAMSCI, 
2002, C19, p. 93). A hegemonia de uma classe nunca é definitiva, exige a sua renovação constante, através de novas estratégias de obtenção de consenso das classes dominadas, cabendo ao intelectual este papel, pois do contrário poderá ocorrer crise de hegemonia.

$\mathrm{Na}$ formação dos intelectuais de uma classe social, Gramsci destaca duas formas mais importantes: o grupo social "originário de uma função essencial no mundo da produção econômica, cria para si, ao mesmo tempo, organicamente, uma ou mais camadas de intelectuais que lhe dão homogeneidade e consciência da própria função, não apenas no campo econômico, mas também no social e político (2014b, C12, p. 15); e através da luta pela assimilação dos intelectuais tradicionais, oriundos da estrutura econômica anterior, à sua ideologia.

Ao mesmo tempo em que Gramsci identifica a função do intelectual na conservação da hegemonia de uma classe, nos casos empíricos analisados, também aponta o papel do intelectual na construção de novos projetos hegemônicos, identificando claramente a necessidade de formação de intelectuais que mobilizem a vontade coletiva das classes subalternas na construção da sua hegemonia. O papel dos intelectuais orgânicos às classes subalternas consiste no processo de formação de uma nova consciência, ou seja, uma nova forma de pensar e de agir na vida social. Em suas palavras, conduzir os sujeitos a "participar ativamente na produção da história do mundo, ser o guia de si mesmo e não mais aceitar do exterior, passiva e servilmente, a marca da própria personalidade" (GRAMSCI, 2014a, C11, p. 94).

Dentre os espaços de formação dos intelectuais, Gramsci destaca os partidos políticos e a escola. O partido político é concebido por Gramsci como o "moderno Príncipe", o sujeito coletivo que representa "a primeira célula na qual se sintetizam os germes de vontade coletiva que tendem a se tornar universais e totais" (2007, C13, p. 16). Os membros de um partido político, em menor ou maior grau, devem ser considerados intelectuais, pois desempenham uma função que "é diretiva e organizativa, isto é, educativa, isto é, intelectual" (2014b, C12, p. 25).

A escola, segundo Gramsci, é um "instrumento para elaborar intelectuais de diversos níveis" (2014b, C12, p. 19). Nesse sentido, "a diferente distribuição dos diversos tipos de escola (clássicas e profissionais) no território "econômico" e as diferentes aspirações das várias categorias destas camadas determinam, ou dão 
forma, à produção dos diferentes ramos de especialização intelectual" (2014b, C12, p. 20). O autor destaca ainda que a complexidade da função intelectual nos diferentes Estados pode ser mensurada pela quantidade de escolas especializadas e pela sua hierarquização: "quanto mais extensa for a 'área' escolar e quanto mais numerosos forem os 'graus' 'verticais' da escola, tão mais complexo será o mundo cultural, a civilização, de um determinado Estado" (2014b, C12, p. 19).

Tendo em vista a importância do papel dos intelectuais na construção da hegemonia das classes subalternas, e o papel da escola na sua formação, o comunista sardo analisou a realidade da escola italiana de sua época, identificando que a sua organização favorecia a manutenção da hegemonia da classe dominante, uma vez que os diferentes tipos de escola existentes eram destinados a diferentes grupos sociais tendo como papel "perpetuar nesses estratos uma determinada função tradicional, dirigente ou instrumental" (2014, C12, p. 50). Contrapondo-se a essa lógica de formação escolar diferenciada entre os diferentes segmentos sociais, e reconhecendo que as instituições são espaços de disputa entre os diferentes interesses de classe, Gramsci propõe:

Se se quer destruir essa trama, portanto, deve-se não multiplicar e hierarquizar os tipos de escola profissional, mas criar um tipo único de escola preparatória (primária-média) que conduza o jovem até os umbrais da escolha profissional, formando-o, durante este meio tempo, como pessoa capaz de pensar, de estudar, de dirigir ou de controlar quem dirige (2014, C12, p. 50).

Com base nessa proposição, Gramsci traça as linhas gerais da "escola unitária" voltada à formação de um novo tipo de homem, autônomo, livre e construtor da sua história. É importante ressaltar que, para o autor, não apenas a escola é importante nessa formação e que a educação "significa muito mais do que a instrução escolar", ela "equivale, simplesmente, às operações fundamentais de hegemonia" (BUTTIGIEG, 2003, p. 47). Na visão gramsciana, a relação pedagógica não se limita aos espaços escolares, ela existe em "toda a sociedade no seu conjunto e em todo indivíduo com relação aos outros indivíduos, entre camadas intelectuais e não intelectuais, entre governantes e governados, entre elites e seguidores, entre dirigentes e dirigidos, entre vanguardas e corpos de exército", concluindo que "toda relação de 'hegemonia' é necessariamente uma relação pedagógica" (2014a, C10, p. 399). 
Nesse sentido, conforme destaca Joseph Buttigieg (2003), a partir da análise dos Cadernos do Cárcere pode-se compreender que "as relações educacionais constituem o próprio núcleo da hegemonia" e que "qualquer análise da hegemonia necessariamente implica um cuidadoso estudo das atividades e das instituições educacionais" (p.47). No entanto, "nem as complexidades da hegemonia nem o significado da educação podem ser entendidos enquanto se pensar a educação exclusivamente em termos de 'relações escolares' (p. 47).

Sem perder de vista essa compreensão ampla da relação entre educação e hegemonia, em razão dos limites de um artigo, nos deteremos na compreensão da escola enquanto espaço formativo, buscando explicitar a proposição de Gramsci como base para a reflexão sobre algumas iniciativas de educação profissional no Brasil, nos dias atuais.

\section{A escola unitária de Gramsci e sua (não) relação com a Educação Profissional no Brasil}

Gramsci observava no contexto educacional italiano que a multiplicação de escolas profissionais (formação para o trabalho), destinadas a formar o novo trabalhador industrial, não constituía uma democratização, pois formava apenas o trabalhador qualificado e não o cidadão com preparação técnico-política, capaz de tornar-se também governante. Conforme ressalta o autor: "O aspecto mais paradoxal reside em que este novo tipo de escola [escola profissional] aparece e é louvado como democrático, quando, na realidade, não só é destinado a perpetuar as diferenças, como ainda a cristalizá-las de forma chinesa". A crítica de Gramsci em relação a esse tipo de escola consistia no fato de que seus currículos eram "cada vez mais especializados" e "preocupadas em satisfazer interesses práticos imediatos, predominam sobre a escola formativa, imediatamente desinteressada" (2014b, C12, p. 50-51).

Para o marxista sardo, a escola é o espaço privilegiado de acesso ao conhecimento sistematizado para as classes populares. Por isso, a simplificação/redução dos currículos dificulta ainda mais o aprendizado, uma vez que estes sujeitos não contam, em sua grande maioria, com o apoio intelectual fora da escola, tampouco já tem desenvolvido previamente os esquemas cognitivos, e 
também físicos, necessários ao trabalho intelectual. Esse tipo de escola contribuiria mais para o abismo entre as classes do que para a diminuição das desigualdades. Gramsci justifica essa análise apontando que,

Decerto, a criança de uma família tradicional de intelectuais supera mais facilmente o processo de adaptação psicofísico; quando entra na sala de aula pela primeira vez, já tem vários pontos de vantagem sobre seus colegas, possui uma orientação já adquirida por hábitos familiares: concentra a atenção com mais facilidade, pois tem 0 hábito da contenção física etc. Do mesmo modo, o filho de um operário urbano sofre menos quando entra na fábrica do que um filho de camponeses ou de que um jovem camponês já desenvolvido para a vida rural (2014b, C12, p. 53).

Estava claro para Gramsci que essa escola, classista, não contribuiria para as mudanças sociais necessárias. A reflexão sobre sua própria experiência enquanto estudante o "convenceram de que a libertação de que a libertação das classes subalternas requeria um esforço educacional concentrado" de forma a superar "os formidáveis obstáculos postos por um sistema educacional público que estava destinado a servir os ricos e perpetuar seu papel de dirigente na sociedade" (BUTTIGIEG, 2003, p. 42-43). A escola única, na sua visão, deveria conjugar a formação humanista e formação para o trabalho, no tempo e nas condições favoráveis para que todos os sujeitos possam adquirir a maturidade e disciplina necessária para a criação intelectual. Além disso, uma condição para que a escola unitária possa abarcar todos os sujeitos, sem divisões de grupos sociais, é de que ela seja pública, alertava Gramsci. “(...) a inteira função de educação e formação das novas gerações deixa de ser privada e torna-se pública, pois somente assim ela pode abarcar todas as gerações, sem divisões de grupos ou castas" (2014b, C12, p. $37)$.

Ao incluir todos na escola unitária, Gramsci alertava para o não rebaixamento ou "facilidades" para o acompanhamento de todos. Pelo contrário, a escola unitária, tendo em vista sua função de ampliação cultural e moral dos sujeitos, deve "implementar todo o rigor e toda a complexidade de conteúdos e saberes acumulados pela humanidade" (SILVA, 2010, p. 200). Conforme assumia Gramsci, "se se quiser criar uma nova camada de intelectuais, chegando às mais altas especializações, a partir de um grupo social que tradicionalmente não desenvolveu 
aptidões adequadas, será necessário superar enormes dificuldades” (2014b, C12, p. 53).

Para superar essas dificuldades, a escola unitária deve apresentar uma organização prática compatível com o seu objetivo: ser de tempo integral, ter seu corpo docente ampliado de forma a apresentar uma menor relação numérica entre professor e aluno, possuir infraestrutura adequada, como bibliotecas, laboratório, refeitórios, dormitórios, material científico, entre outros. Não apenas em relação às condições materiais e humanas, o modelo didático-pedagógico da escola unitária também deve ser diferenciado, ressaltava Gramsci: partindo-se das primeiras noções de instrução (ler, escrever, fazer contas, geografia, história), deve-se estimular a autonomia intelectual, a disciplina dos estudos, encarando o estudo como um trabalho "muscular-nervoso", com vistas a desenvolver os elementos essenciais para a construção de uma nova concepção de mundo, de forma autônoma. Em suas palavras:

Do ensino quase puramente dogmático, no qual a memória desempenha um grande papel, passa-se à fase criadora ou de trabalho autônomo e independente; da escola com disciplina de estudo imposta e controlada autoritariamente, passa-se a uma fase de estudo ou de trabalho profissional na qual a autodisciplina intelectual e a autonomia moral são teoricamente ilimitadas (2014b, C12, p. 39)

A escola unitária tem o trabalho como princípio educativo, porém não é uma escola profissionalizante desde o início, como na realidade italiana. Gramsci criticava a especialização precoce dos estudantes, apontando que essa escola do trabalho era na verdade a escola do emprego ${ }^{5}$, que conforma os jovens à realidade econômica, intelectual e moral vigente. O trabalho como princípio educativo é concebido por Gramsci como categoria basilar da sociabilidade humana, a forma como os sujeitos se inserem no meio social. Nesse sentido, defendia que "o advento da escola unitária significa o início de novas relações entre trabalho intelectual e trabalho industrial não apenas na escola, mas em toda a vida social. O princípio unitário, por isso, irá se refletir em todos os organismos de cultura, transformando-os e emprestando-Ihes novo conteúdo" (GRAMSCI, 2014b, C12, p. 40-41). O trabalho nesse sentido, não é visto como uma atividade específica do processo produtivo,

\footnotetext{
${ }^{5}$ No texto La scuola del lavoro, escrito em 1916, Gramsci afirma que "A escola do trabalho tem sido sacrificada à escola do emprego" (apud SHLESENER, 2002, p. 67).
} 
mas sim como "a forma própria através da qual o homem participa ativamente na vida da natureza, visando a transformá-la e socializá-la cada vez mais profunda e extensamente" (p. 43).

No entanto, a preparação para o trabalho industrial não deixa de ser importante na formação do intelectual das classes subalternas. Porém, sua formação não pode estar baseada apenas na técnica-trabalho, esta deve chegar à "técnica-ciência e à concepção humanista histórica, sem a qual permanece 'especialista' e não se torna 'dirigente' (especialista + político) (GRAMSCI, 2014b, C12, p. 54). Nesse sentido, a última fase da escola unitária (que vai até os quinze ou dezesseis anos) "deve ser concebida e organizada como a fase decisiva, na qual se tende a criar os valores fundamentais do 'humanismo', a autodisciplina intelectual e a autonomia moral necessárias a uma posterior especialização, seja ela de caráter científico, seja de caráter imediatamente prático-produtivo" (p. 39). Ao contrário das escolas profissionais italianas de sua época, Gramsci defendia que a escola unitária "deveria assumir a tarefa "de inserir os jovens na atividade social, depois de tê-los elevado a um certo grau de maturidade e capacidade para a criação intelectual e prática e a uma certa autonomia na orientação e na iniciativa. (p. 36).

A proposição de Gramsci quanto à escola unitária, bem como suas críticas à escola profissional italiana de sua época são elementos importantes para análise e proposições no campo da educação profissional no Brasil. Pode-se dizer que tanto as escolas profissionais criticadas por Gramsci, quanto as tentativas de elaboração de um projeto pedagógico com base na escola unitária podem ser encontradas na realidade brasileira.

Conforme destaca Moraes (2015), a iniciativa do Estado Nacional brasileiro com vistas à formação do novo trabalhador exigido com o advento da industrialização no país, foi inspirada na escola profissional italiana criticada por Gramsci. As Leis Orgânicas do Ensino, também conhecidas como Reforma Capanema, formuladas nesse período, adequavam o sistema educacional para o atendimento das demandas do capitalismo industrial que se instalava no país, passando a educação profissional a ter um papel especial nesse contexto, constituindo-se num ramo da educação básica destinado à formação de trabalhadores a partir de diversas especializações técnicas. Essa iniciativa 
configurou uma dualidade educacional no sistema público de ensino: de um lado a formação profissional e, de outro, a formação propedêutica.

Aliado a isso, essa reforma institucionalizou o projeto educacional da Confederação Nacional da Indústria, a partir da criação da organização empresarial denominada Serviço Nacional de Aprendizagem Industrial - SENAI, (Decreto-Lei no 4.048, de 22/01/1942) que já vinha sendo desenvolvido no Estado de São Paulo, celeiro das primeiras indústrias no país ${ }^{6}$. Baseada no modelo produtivo das indústrias, o taylorismo/fordismo, a formação profissional desenvolvida pelo SENAI baseava-se na aprendizagem da operacionalização de equipamentos e execução de tarefas, o que se tornava muito mais eficiente se realizada no contexto da prática. Com isso, além da aprendizagem das técnicas, incluíam-se como conteúdos formativos a disciplina e o modelo de administração das fábricas, contribuindo na formação do trabalhador necessário para o "bom andamento" do processo produtivo e da reprodução das relações sociais capitalistas. Formava-se assim o especialista necessário ao desempenho de determinadas funções no processo produtivo, em detrimento do cidadão com preparação técnico-política, capaz de tornar-se também governante, conforme criticava Gramsci a partir da realidade italiana.

A partir do final da década de 1960, sob a égide da Ditadura civil-militar no Brasil, o modelo economicista de educação profissional é aprofundado por meio da ideologia do "capital humano", que identifica a educação como fator de produtividade e desenvolvimento econômico (MACHADO, 2010). Esse modelo de educação profissional se perpetuou nas políticas educacionais no país de forma predominante, até os anos 2000, apesar dos movimentos contrários por parte de organizações e movimentos educacionais.

Com a elaboração da nova Constituição Federal, no final da década de 1980, o debate sobre a educação profissional enquanto formação integral do ser humano, com base no princípio da politecnia e escola unitária de Gramsci, ganhou força no país, buscando constituir-se enquanto princípio na nova Lei de Diretrizes e Bases da Educação Nacional (LDB). No entanto, com a emergência do neoliberalismo na década de 1990, novos projetos educacionais entraram em interlocução com o

\footnotetext{
${ }^{6}$ A partir da criação do SENAI, o projeto da burguesia para a formação dos trabalhadores ampliou seu espaço de atuação. Hoje já são mais 4 instituições que atuam no setor educacional: SESI (Serviço Social da Indústria); SENAC (Serviço Nacional de Aprendizagem Comercial); SESC (Serviço Social do Comércio); SENAR (Serviço Nacional de Aprendizagem Rural), as quais constituem o Sistema S.
} 
governo federal, gerando um jogo de forças desiguais que se reverteu em um processo de "contrarreforma" ao projeto democrático de educação e sociedade que a Constituição Federal de 1988 apontava. Sendo resultado de uma intensa disputa de projetos que durou 8 anos, a LDB aprovada em 1996 consolidou a perspectiva do governo, claramente identificada com a perspectiva neoliberal (SAVIANI, 2004).

Em relação à educação profissional, a nova LDB foi bastante vaga, criando o espaço necessário para a publicação de um Decreto logo em seguida. O Decreto 2.208, implementado pelo Governo FHC em 1997, proibia a formação profissional integrada ao ensino médio e regulamentava formas "fragmentadas e aligeiradas de educação profissional em função das alegadas necessidades do mercado" (RAMOS; FRIGOTTO; CIAVATTA, 2005, p. 25), tendo gerado fortes críticas de entidades, organizações e atores do campo educacional.

Com a eleição do candidato do Partido dos Trabalhadores para a Presidência da República, em 2002, ampliaram-se as expectativas dos setores progressistas em retomar o debate travado na década de 1980. A partir de um processo de disputas, um avanço obtido foi a retomada legal da possibilidade de integração entre educação básica e educação profissional, com a publicação de novo Decreto (Decreto 5154/2004), que substituiu o da década anterior. Essa integração permitiria uma formação humana e científica sólida a par de uma especialização técnica, possibilitando o desenvolvimento de processos formativos que elevariam o trabalhador ao nível "especialista + político", como se referia Gramsci.

O novo Decreto representou um importante avanço ao retomar as bases jurídicas para a oferta da educação profissional integrada à educação básica. Porém, ao mesmo tempo, como resultado de um conjunto de disputas ${ }^{7}$ expressa algumas contradições: reproduziu o modelo de Decreto, ao invés de Lei, o que seria mais democrático e legítimo enquanto instrumento legal; preservou a oferta de cursos dissociados da educação básica; e "caminhou" por 08 (oito) anos a par das

\footnotetext{
${ }^{7}$ Gaudêncio Frigotto, Maria Ciavatta e Marise Ramos, relatam, enquanto participantes desse processo, a existência de pelo menos três propostas diferentes que atuaram nessa disputa: "uma primeira posição expressa em três documentos defendia a ideia ou tese de que cabe apenas revogar o Decreto n. 2.208/97 e pautar a elaboração da política de Ensino Médio e Educação Profissional, de uma parte pelo fato de a LDB em vigor (Lei n. 9.394/96) contemplar as mudanças que estão sendo propostas e, de outra, por se entender que tentar efetivar mudanças por decreto significa dar continuidade ao método impositivo do governo anterior. Uma segunda posição é expressa, mais diretamente, por um documento que se posiciona pela manutenção do atual Decreto $\mathrm{n}$. 2.208/97 e outros documentos que indiretamente desejariam que as alterações fossem mínimas. Por fim, uma terceira posição, que consta de um número mais significativo de documentos, direta ou indiretamente partilha da ideia da revogação do Decreto n. 2.208/97 e da promulgação de um novo Decreto" (FRIGOTTO, CIAVATTA e RAMOS, 2005, p. 23-24).
} 
Diretrizes Curriculares para a Educação Profissional Técnica de Nível Médio elaboradas com base no antigo Decreto ${ }^{8}$.

Na visão de Ramos (2011, p. 105), a operacionalização do novo Decreto com base nas diretrizes emanadas do antigo marco legal acabou dando "continuidade à política curricular do governo anterior, marcada pela ênfase no individualismo e na formação por competências voltadas para a empregabilidade". Apenas em 2012, também fruto de intensas disputas e debates, é que foram publicadas as Diretrizes Curriculares para a Educação Profissional Técnica de Nível Médio, tendo como base as normativas do Decreto 5154/2004, a partir da Resolução CNE/CEB 06/2012.

Essa primeira experiência de tentativa de mudança na concepção e políticas de educação profissional em curso evidenciou, conforme analisam Frigotto, Ciavatta e Ramos, que o Governo não colocava em pauta mudanças estruturais, em razão de ser "expressão de um bloco heterogêneo dentro do campo da esquerda e com alianças cada vez mais conservadoras" (2005, p. 26). O uso de decreto, enquanto forma legal de mudança, e as contradições que ele carrega, representou, nesse cenário, a forma possível para - em face das forças conservadoras no Congresso Nacional e da ausência de forças políticas no próprio governo para sustentação de uma mudança estrutural na política da área - instituir as bases para a "(re)construção de princípios e fundamentos da formação dos trabalhadores para uma concepção emancipatória dessa classe" (2005, p. 30).

Quanto à inserção da profissionalização na educação básica, é importante destacar as divergências entre os educadores intérpretes de Gramsci. Na visão de Nosella, por exemplo, o ensino médio, com base na concepção de educação gramsciana, com vistas a uma "escola média nacional", deveria transformar-se "num poderoso instrumento de cultura geral, moderno, opondo-se à onda crescente de sua profissionalização" (2016, p. 86). Para o autor, o ensino médio é uma etapa de ensino da "plenitude e da maturidade da pessoa, quando o jovem aprende a produzir e dirigir a si mesmo, como pressuposto para produzir e dirigir a sociedade" (p. 65) e a dualidade estrutural da sociedade que obriga parcela dos jovens a ingressarem precocemente no mercado de trabalho não justifica o "abandono, por parte do Estado, do ensino médio público não profissionalizante" (p. 66).

\footnotetext{
${ }^{8}$ Durante esse período as Diretrizes aprovadas em 1999, sob a Resolução CNE/CEB n. 04/99, foram atualizadas pela Resolução CEB 01/2005, que incluiu a possibilidade de oferta da forma Integrada entre ensino médio e curso técnico, aprovada pelo novo Decreto.
} 
Embora concordando com a perspectiva de uma educação unitária não profissionalizante, outros educadores reconhecem como importante e legítima a possibilidade da profissionalização no ensino médio, admitindo-a "quando associada à educação intelectual, física e tecnológica" (MOURA, LIMA FILHO, RIBEIRO, 2015, p. 1066), tendo em vista as necessidades da classe trabalhadora no contexto atual. A proposta gramsciana de uma formação unitária, na visão destes autores, refere-se "a uma possibilidade futura a ser materializada em uma sociedade na qual a classe trabalhadora tenha ascendido ao poder político" (p. 1066), e o ensino médio integrado pode ser encarado como uma proposta educacional de "travessia" para esse novo contexto.

Nos marcos de uma sociedade capitalista, não se poderia prescindir das necessidades da classe trabalhadora, e o ensino médio integrado ao ensino técnico apresenta-se como uma proposta de formação científica sólida associada ao domínio de técnicas de trabalho que permitem ao jovem os meios para a produção de sua subsistência no mercado de trabalho atual. Nessa direção, também Frigotto, Ciavatta e Ramos (2005, p. 43) se posicionam:

Se a preparação profissional no ensino médio é uma imposição da realidade, admitir legalmente essa necessidade é um problema ético. Não obstante, se o que se persegue não é somente atender a essa necessidade, mas mudar as condições em que ela se constitui, é também uma obrigação ética e política garantir que o ensino médio se desenvolva sobre uma base unitária para todos. Portanto, o ensino médio integrado ao ensino técnico, sob uma base unitária de formação geral, é uma condição necessária para se fazer a "travessia" para uma nova realidade.

Dessa perspectiva, aponta-se que o governo Lula promoveu avanços na educação profissional, também, ao articular a Educação de Jovens e Adultos à oferta de ensino técnico e formação inicial e continuada, através do Decreto 5.478/2005 que instituiu o Programa Nacional de Integração da Educação Profissional com a Educação Básica na Modalidade de Educação de Jovens e Adultos, o PROEJA. Essa política proporcionou significativo avanço na área de educação de jovens e adultos, pois promoveu a elevação de escolaridade juntamente com a formação profissional e a partir de um currículo integrado, representando uma conquista das lutas pelo direito à educação e de "resistências à lógica fragmentária, focalizada, compensatória e reducionista das ações de 
formação implementadas anteriormente" (RAMOS, 2011, p. 106). Aliado a isso, a criação dos Institutos Federais de Educação, Ciência e Tecnologia (IFs), em 2008, os quais, por força de Lei, devem ofertar $50 \%$ das suas vagas em cursos técnicos, prioritariamente, integrados ao ensino médio, e o Programa Brasil Profissionalizado, voltado para o financiamento da oferta de ensino médio integrado nas redes estaduais de ensino, fortaleceu a oferta de educação profissional integrada à educação básica.

No entanto, como a disputa pela hegemonia é um processo permanente, e o fato de as conquistas estabelecidas no campo político não terem sido acompanhadas de mudanças econômicas estruturais (GRAMSCI, 2007), estes avanços ficaram sujeitos às alterações na própria correlação de forças que os produziram. Como expressão das disputas entre capital e trabalho, o projeto de educação profissional levado à cabo nos anos 1990 permaneceu latente, conquistando cada vez mais espaço nas políticas governamentais.

Assim, a par dessas iniciativas progressistas, persistiram as escolas e cursos de formação profissional destinados à formação do especialista em determinada tarefa no processo produtivo, seja através das instituições ligadas ao Sistema S, seja através de programas de formação profissional no âmbito dos governos ${ }^{9}$, como $^{\circ}$ resultado de um governo marcado pela defesa dos direitos dos trabalhadores e pela sua governabilidade sustentada em políticas de conciliação com os interesses da burguesia (SINGER, 2009; 2015).

Nesse contexto, é possível compreender a emergência do Pronatec (Programa Nacional de Acesso ao Ensino Técnico e Emprego), criado no primeiro Governo Dilma (PT 2011-2014), pela Lei 12.513/2011, o qual fomentou/fomenta o desenvolvimento da educação profissional a partir da concepção de formação especializada para o mercado de trabalho, especialmente por meio da iniciativa denominada Bolsa-Formação ${ }^{10}$. Apesar de prever diferentes possibilidades de oferta

\footnotetext{
9 Desde a década de 1960 vários programas de formação profissional voltada às demandas do mercado de trabalho foram desenvolvidos em âmbito nacional: como o PIPMO (Programa Intensivo de Preparação de Mão-de-Obra), na década de 1960, o PLANFOR (Plano Nacional de Qualificação do Trabalhador) na década de 1990, e o PNQ (Programa Nacional de Qualificação Profissional) nos anos 2000.

${ }^{10} \mathrm{~A}$ Bolsa Formação é uma das iniciativas que compõem o Pronatec, a qual tem recebido o maior volume de recursos (50\% do montante destinado ao Programa até 2016, conforme dados do Portal da Transparência). Essa iniciativa consiste no financiamento de matrículas em cursos técnicos e de formação inicial e continuada em unidades de ensino existentes - redes públicas e privadas. Há duas modalidades: Bolsa-Formação Estudante - oferta cursos técnicos e a Bolsa-Formação Trabalhador -
} 
de cursos de formação profissional ${ }^{11}$ e envolver instituições públicas e privadas no seu desenvolvimento, o Pronatec Bolsa-Formação atingiu 4,6 milhões de matrículas no ano de 2016 com o seguinte cenário: $77,3 \%$ das matrículas em cursos Formação inicial e continuada, os quais são dissociados da educação básica e apresentam uma carga horária que varia entre 160 e 400 horas, e 78,8\% foram desenvolvidas por instituições privadas, sendo que 66,7\%, exclusivamente, por instituições do Serviço Nacional de Aprendizagem, o Sistema S (SIMEC, 2017).

Além da "privatização" do conteúdo, a predominância do Sistema S na oferta dos cursos Pronatec representa a privatização no uso dos recursos públicos e legitima o Estado enquanto financiador da iniciativa privada, a qual atende os interesses do capital. Essa realidade, na contramão do que propunha a escola unitária de Gramsci, por ser desenvolvida a partir da atuação de uma organização que representa os interesses da classe burguesa é atravessada pelos interesses dessa classe.

Aparentemente, o Pronatec democratiza o acesso à formação profissional, pois possibilita que sujeitos em diferentes níveis de escolaridade possam se qualificar para o ingresso no mercado de trabalho. No entanto, como já dizia Gramsci esse tipo de escola contribui mais para perpetuar as diferenças e desigualdades de classe, do que para a mudança social. Apesar dos grandes números atingidos, do ponto de vista da formação do trabalhador se esta iniciativa não estiver acompanhada de políticas de elevação da escolaridade, a partir de uma formação humanista sólida constituir-se-á em um grande "castelo de areia" (FRIGOTTO, 2013).

Análises realizadas sobre o Pronatec apontam, em geral, a preocupação com - volume de transferência de recursos públicos para a iniciativa privada, a secundarização, ou quase anulação, da integração entre educação básica e formação profissional no âmbito desta política e suas semelhanças com programas de formação profissional desenvolvidos no passado, como o PIPMO e o PLANFOR (LIMA, 2012; MACHADO,2013; GARCIA, 2013; MOURA, 2013; FRANZOI et al, 2013). Por outro lado, são sinalizados alguns méritos do Programa, como a tentativa de superar a pulverização de iniciativas de formação profissional no âmbito dos

oferta cursos de formação inicial ou continuada (FICs). Do total de recursos investidos nessa iniciativa, mais de $70 \%$ foram utilizados pelo Sistema S.

${ }^{11}$ Cursos técnicos concomitantes e subsequentes ao ensino médio, Proeja e cursos de formação inicial e continuada. 
ministérios, reunindo-as no âmbito do Ministério da Educação, sem deixar de integrar-se com as demais políticas sociais do governo, e o fato de concentrar a oferta de cursos pela Rede Federal de Educação Profissional e Tecnológica e pelo Sistema $\mathrm{S}$, ao contrário do $\mathrm{PNQ}$ e do PLANFOR que mobilizavam um grande número de instituições de diversas naturezas, inclusive ONGs (CASTIONI, 2013).

No entanto, as análises que compreenderam investigação empírica em instituições que ofertam cursos pelo Pronatec revelam a elevada evasão nos cursos, em especial nos cursos técnicos concomitantes, em razão da dupla jornada dos estudantes ao frequentar duas instituições de ensino e conciliar, em muitos casos, também o trabalho, não se confirmando, assim, o objetivo do programa em democratizar o acesso à educação profissional técnica de nível médio (SALDANHA, 2015); e a "inclusão excludente" dos estudantes nos cursos Pronatec no âmbito de um Instituto Federal, em razão das condições diferenciadas de corpo docente e pedagógico-administrativas (RAMOS, 2014), promovidas pela forma de contratação dos profissionais por meio do pagamento de bolsas.

Com o golpe parlamentar de 2016 (LÖWY, 2016), o Pronatec BolsaFormação ganhou uma nova "roupagem" a partir do MedioTec, que oferta cursos técnicos na forma concomitante, por meio de instituições públicas e privadas, para estudantes de escolas públicas de ensino médio, inclusive na modalidade a distância. Essa mudança de foco tem sido apontada por vários estudiosos (ARELARO, 2017; MOTTA, 2017; FRIGOTTO, 2017) como uma forma de antecipação da Reforma do Ensino Médio, aprovada pela Lei 13.415 de 15 de fevereiro de 2017, que reduz a base formativa comum nessa etapa de ensino e insere itinerários formativos de "escolha" dos estudantes, entre eles a formação técnica, permitindo o estabelecimento de parcerias público-privadas, como é o caso do MedioTec.

\section{Considerações finais}

Apesar da distância histórica - quase um século - entre as formulações críticas e propositivas de Gramsci em relação à escola italiana, pode-se observar que elas continuam válidas para o nosso contexto. $O$ projeto de educação profissional vigente em nosso país, excetuando-se algumas iniciativas contra 
hegemônicas, visa atender à demanda de formar bons trabalhadores, mas que pensem no limite da execução de sua atividade profissional, tal como criticava Gramsci na realidade italiana.

Por sua função estratégica na construção e manutenção da hegemonia de classe, a educação é um espaço de disputa de diferentes projetos educacionais. As políticas educacionais expressam os diferentes interesses emanados da sociedade civil e da sociedade política, ora avançando para uma concepção progressista de educação, ora retrocedendo e/ou convivendo com iniciativas contraditórias e híbridas.

A construção da escola única continua sendo um objetivo a ser atingido, para uma parcela dos profissionais e militantes do campo educacional. Uma escola que possibilite a todos os sujeitos a construção da autonomia intelectual como ferramenta para a mudança da realidade social, a partir de uma construção histórica envolvendo conscientemente a classe trabalhadora.

\section{Referências}

ARELARO, L. Reforma do Ensino Médio: o que querem os golpistas. Revista Retratos da Escola, Brasília, v. 11, n. 20, p. 11-17, jan./jun. 2017.

CASTIONI, R. Planos, Projetos e Programas de educação profissional: agora é a vez do Pronatec. Sociais e Humanas, Santa Maria, v. 26, n. 01, jan/abr 2013.

FRANZOI, N. L.; SILVA, C. O. B, COSTA, R. de C. D. PROEJA e PRONATEC: ciclo de políticas, políticas recicladas. Políticas Educativas, Porto Alegre, v. 6, n.2, p. 84100, 2013.

FRIGOTTO, G. Ensino Médio e técnico profissional: disputa de concepções e precariedade. Le Monde Diplomatique, Edição 68, Março 2013.

FRIGOTTO, G; CIAVATTA, M; RAMOS, M. A Gênese do Decreto 5.154/2004: um debate no contexto controverso da democracia restrita. In: FRIGOTTO, G; CIAVATTA, M; RAMOS, $M$. Ensino médio integrado: concepções e contradições. São Paulo: Cortez, 2005.

GRAMSCI, A. Cadernos do Cárcere. V. 1. Introdução ao Estudo da Fisolofia. A filosofia de Benedetto Croce. $7^{a}$ ed. Rio de Janeiro: Civilização Brasileira, 2014a.

GRAMSCI, A. Cadernos do Cárcere. V. 2. Os intelectuais. O princípio educativo. Jornalismo. $7^{\underline{a}}$ ed. Rio de Janeiro: Civilização Brasileira, 2014b.

GRAMSCI, A. Cadernos do Cárcere. V. 3. Maquiavel e Notas Sobre o Estado e a Política. 3aㅡ ed. Rio de Janeiro: Civilização Brasileira, 2007.

GRAMSCI, A. Cadernos do Cárcere. V. 5. O Rissorgimento. Notas sobre a história da Itália. Rio de Janeiro: Civilização Brasileira, 2002. 
LIMA, M. A educação profissional no governo Dilma: Pronatec, PNE e DCNEMs. RBPAE - v. 28, n. 2, p. 495-513 mai/ago. 2012.

LÖWY, M. Da tragédia à farsa: o golpe de 2016 no Brasil. In:JINKINGS, I.; DORIA, K.; CLETO, M.(org.) Por que gritamos golpe? Para entender o impeachment e a crise política no Brasil. São Paulo: Boitempo, 2016.

MACHADO, L. Capital humano. In: OLIVEIRA, D.A.; DUARTE, A.M.C.; VIEIRA, L.M.F. DICIONÁRIO: trabalho, profissão e condição docente. Belo Horizonte:

UFMG/Faculdade de Educação, 2010.

MACHADO, M. M.; GARCIA, L. T. Passado e presente na formação de jovens e adultos trabalhadores. Revista Brasileira de Educação de Jovens e Adultos, v. 1, n. 1, 2013.

MORAES, C. S. V. Trabalho e Educação como pauta do GT Trabalho e Educação da ANPED: algumas considerações sobre o campo de pesquisa. Revista Trabalho Necessário, ano 13, número 20, 2015.

MOTTA, V. C. da; FRIGOTTO, G. Por que a urgência da reforma do ensino médio? Medida Provisória no 746/2016 (Lei no 13.415/2017). Educação e Sociedade, Campinas, v. 38, no. 139, p.355-372, abr.-jun., 2017.

MOURA, D. H. Ensino Médio e Educação Profissional no Brasil nos anos 200: movimentos contraditórios. In: MOURA, Dante Henrique (org.). Produção do

Conhecimento, Políticas Públicas e Formação Docentes em Educação Profissional. Campinas, SP: Mercado de Letras, 2013.

MOURA, D. H.; LIMA FILHO, D.; RIBEIRO, M. Politecnia e formação integrada: confrontos conceituais, projetos políticos e contradições históricas da educação brasileira. Revista Brasileira de Educação, v. 20 n. 63 out.-dez. 2015.

NOSELLA, P. Ensino Médio à luz do pensamento de Gramsci. Campinas, SP: Editora Alínea, 2016.

PORTELLI, H. Gramsci e o Bloco Histórico. 6aㅗ ed. Rio de Janeiro: Paz e Terra, 2002.

RAMOS, M. Educação Profissional: história e legislação. Curitiba: Instituto Federal do Paraná, 2011.

RAMOS, M. S. Limites e Possibilidades do PRONATEC como ação governamental de ampliação da Educação Profissional no Brasil: uma análise a partir da experiência do IFRJ. Nova Iguaçu: 2014, 204 p. Dissertação [Mestrado em Educação] - a Programa de Pós-graduação em Educação, Contextos Contemporâneos e Demandas Populares - UFRRJ.

SALDANHA, L. de L. W. O PRONATEC e a proclamada política de democratização da educação profissional técnica de nível médio: acesso, abandono e permanência a partir de um estudo de caso. 29/03/2016 $282 \mathrm{f}$. Doutorado em EDUCAÇÃO Instituição de Ensino: UNIVERSIDADE FEDERAL DO PARANÁ, Curitiba.

SAVIANI, D. A Nova Lei da Educação: trajetória, limites e perspectivas. 9a ed. Campinas, SP: Autores Associados, 2004. (Coleção educação contemporânea)

SCHLESENER, A. H. Revolução e Cultura em Gramsci. Curitiba: UFPR, 2002. 
SECCO, L. Gramsci e a Revolução. São Paulo: Alameda, 2006.

SILVA, D. R. Intelectuais, cultura e escola única no pensamento políticopedagógico de Antonio Gramsci. Dissertação de Mestrado. Programa de PósGraduação em Educação da Faculdade de Educação da Universidade de São Paulo. 267 fl. 2010.

SIMEC (Sistema Integrado de Monitoramento Execução e Controle do Ministério da Educação) Disponível no endereço: http://painel.mec.gov.br/ Consulta realizada em agosto de 2017.

SINGER, André. Cutucando onças com varas curtas - O ensaio desenvolvimentista no primeiro mandato de Dilma Rousseff (2011-2014). Novos estudos, CEBRAP, São Paulo, n. 102, 2015.

SINGER, André. Raízes Sociais e Ideológicas do Lulismo. Novos estudos, CEBRAP, São Paulo, n. 85, 2009.

Recebido em: 29 de julho de 2018. Aprovado em: 17 de setembro de 2018. Publicado em: 22 de novembro de 2018. 